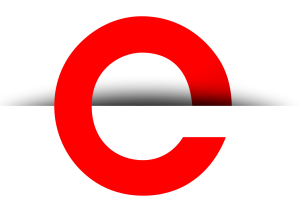

U T S

e PRES S
PORTAL Journal of

Multidisciplinary

International Studies

Vol. 17, No. $1 / 2$

Jan 2021
CULTURAL WORK

\section{Pleas Through a Glass}

\section{Chad Hammond}

Corresponding author(s): Chad Hammond, 649 Evergreen Boulevard Saskatoon, SK, Canada S7W 0Y7. nascent.knowledgedgmail.com

DOI: http://dx.doi.org/10.5130/pjmis.v17i1-2.7419

Article History: Received 12/09/2020; Accepted 05/11/2020; Published 28/01/2021

\section{Abstract}

This poem enters one of many craters left by the COVID-19 pandemic and bears witness to the divisions exposed within.

is an Open Access article distributed under the terms of the Creative Commons Attribution 4.0 International (CC BY 4.0) License (https:// creativecommons.org/ licenses/by/4.0/), allowing third parties to copy and redistribute the material in any medium or format and to remix, transform, and build upon the material for any purpose, even commercially, provided the original work is properly cited and states its license.

Citation: Hammond, C. 2021. Pleas Through a Glass. PORTAL Journal of Multidisciplinary International Studies, 17:1/2, 125-126. http://dx.doi.org/10.5130/ pjmis.v17i1-2.7419

ISSN 1449-2490 | Published by UTS EPRESS I http://epress. lib.uts.edu.au/ojs/index.php/ portal

\section{Pandemic; COVID-19; Essential workers; Racism; Women}

Tucked away from sight

the new are catching the old.

Third today, she coughs,

wheeling the chair to the window

where the young glares await.

How does one entrust to an other

so hated the care of her mother?

Tonight behind this glass she asks

Please Mme, thank you, not mine,

lift your hand to hers before you go.

\#Stayhome, there in-between

shuttered windows and shattered screens.

Post all your juvenile pleas

to the other side of these

sublimate the fate you dread.

A petried mind cuts and swipes 
e P R E S S her way back to the others.

Tonight behind this glass she asks

Please, peers, take these times

broadcast a future beyond boredom.

Big boxes, big windows

bring a glow to a shutdown heart.

Food before virtue, 'cept for the workers

underneath transparent skin

they move 'long this hungry machine.

She works the stocks, runs the yards,

Pushed on all fronts much too far.

Tonight behind this glass she asks

Please, sir, you don't need to shout,

What are you searching for?

Downtown, still life displays

the quiet ruptured storefronts,

streets rattle the shades

with fury, her boy's life pressed

into a fragile photo frame.

She reads signs of foreclosure

est.'74, gone today.

Tonight behind this glass she asks

Please, God, bring to those past eyes

a glimmer beyond their wake. 